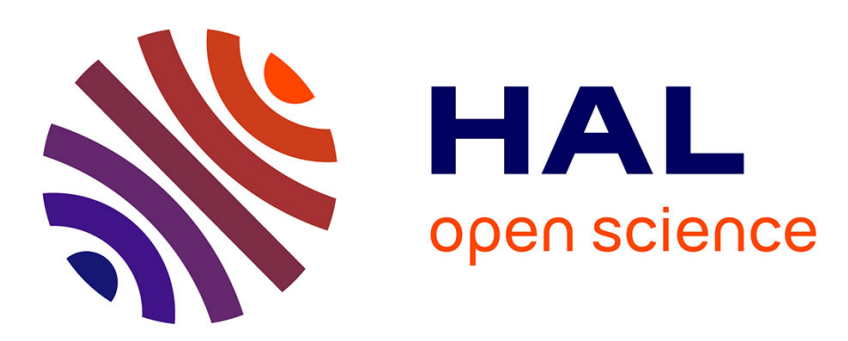

\title{
Electrochemically Assisted Generation of Silica Deposits Using a Surfactant Template at Liquid/Liquid Microinterfaces
}

\author{
Lukasz Poltorak, Grégoire Herzog, Alain Walcarius
}

\section{- To cite this version: \\ Lukasz Poltorak, Grégoire Herzog, Alain Walcarius. Electrochemically Assisted Generation of Silica Deposits Using a Surfactant Template at Liquid/Liquid Microinterfaces. Langmuir, 2014, 30 (38), pp.11453-11463. 10.1021/la501938g · hal-01498771}

\section{HAL Id: hal-01498771 \\ https://hal.univ-lorraine.fr/hal-01498771}

Submitted on 10 Nov 2018

HAL is a multi-disciplinary open access archive for the deposit and dissemination of scientific research documents, whether they are published or not. The documents may come from teaching and research institutions in France or abroad, or from public or private research centers.
L'archive ouverte pluridisciplinaire HAL, est destinée au dépôt et à la diffusion de documents scientifiques de niveau recherche, publiés ou non, émanant des établissements d'enseignement et de recherche français ou étrangers, des laboratoires publics ou privés. 


\title{
Electrochemically assisted generation of silica deposits using a surfactant template at liquid/liquid micro-interfaces
}

Lukasz Poltorak, Grégoire Herzog*, and Alain Walcarius

Laboratoire de Chimie Physique et Microbiologie pour 1'Environnement (LCPME), UMR 7564, CNRS - Université de Lorraine, 405 rue de Vandoeuvre, 54600 Villers-les-Nancy, France.

*gregoire.herzog@univ-lorraine.fr

Keywords: mesoporous silica, micro-ITIES, ion transfer voltammetry, interfacial electrodeposition, liquid/liquid interface

This document is a postprint. Final version has been published in Langmuir, 2014, 30, 11453-11463 (https://doi.org/10.1021/la501938g).

\begin{abstract}
The electrochemically assisted generation of mesoporous silica deposits at arrays of microscopic liquid/liquid interfaces was investigated. Ion transfer voltammetry was used in order to initiate the formation of silica material by electrochemical transfer of template species (cetyltrimethylammonium, $\mathrm{CTA}^{+}$), initially present in the organic phase, to the aqueous phase containing the hydrolyzed silica precursors (tetraethoxysilane, TEOS). The deposition mechanism was investigated using cyclic voltammetry, based on the analysis of diffusion layer profiles of $\mathrm{CTA}^{+}$species from the organic side of the interface. The morphology of the deposits varied from hemispherical to almost flat with the potential scan rate, the spacing factor of the micro-interfaces array supporting the liquid/liquid interfaces, or the initial $\mathrm{CTA}^{+}$and $\mathrm{TEOS}$ concentrations, as evidenced by scanning electron microscopy and profilometry analyses. The amount of deposited material can be related to the amount of $\mathrm{CTA}^{+}$species passing across the liquid/liquid interfaces. Confocal Raman spectroscopy was used to confirm the presence of surfactant-templated silica
\end{abstract}


deposits and to analyze the effectiveness of calcination in removing the organic molecules filling the interior of the pores. After template removal, the mesoporous network became accessible to external reagents, as checked by interfacial alkylammonium cations transfer, suggesting a possible analytical interest of such modified micro liquid/liquid interfaces.

\section{Introduction}

Determination of ionic analytes at the ITIES ranges from inorganic molecules ${ }^{1,2}$ to organic compounds and even biochemically important derivatives. ${ }^{3}$ Despite unique attractive features (e.g., detection not restricted to electron transfer reactions ${ }^{4}$ or defect-free 'working' liquid/liquid interface $^{5}$ ), electroanalysis at the ITIES still suffers from a lack of selectivity. This drawback can be somewhat overcome by introducing ionophores to the organic phase, which selectively transfer target ions, ${ }^{6}$ or by interfacial modification. ${ }^{7,8}$ The latter was reported by Dryfe et al. in a series of papers, where the liquid/liquid interface was modified $e x$-situ with a zeolite membrane initially grown on a mercury surface. The molecular sieving properties of the zeolite allowed selective transfer of small cations in the presence of larger ones (i.e., respectively smaller and larger than the size of pinholes) and considerably increased the potential window when using an appropriate organic electrolyte. ${ }^{7,8}$ When sodium zeolite-Y was employed to modify the ITIES, size selectivity was completed with charge selectivity (anions exclusion). ${ }^{9}$ However, zeolite-based ITIES membranes still suffer from limited film porosity control (restricted to the microporous domain) and from the impossibility of further functionalization (e.g., with organic groups), which could be basically achieved with silica-based mesoporous materials, for instance.

Mesoporous materials play a crucial role in electrochemistry, ${ }^{10}$ but they have been almost exclusively restricted to solid electrodes to date. Mesoporous silica particles exhibiting high specific surface area and an ordered three-dimensional structure made of highly open spaces (as typically prepared by the sol-gel technology in the presence of surfactant templates ${ }^{11}$ ), have been exploited in 
carbon paste electrodes for sensing applications. ${ }^{12}$ Continuous thin films of surfactant-templated mesoporous silica can be also generated onto solid electrode surfaces and used for electroanalytical purposes. $^{12,13}$ In this respect, the combination between sol-gel chemistry together with electrochemical methods has emerged as an easy and straightforward way to generate mesoporous silica thin films on conducting supports with pores oriented perpendicular to the surface by electrochemically assisted self-assembly method. ${ }^{14,15}$ This method can be extended to the deposition on ultramicroelectrodes, ${ }^{16}$ and to the generation of functionalized and oriented thin films exhibiting promising properties for electrochemical sensing. ${ }^{17,18,19,20}$ To date, only very few examples are available, dealing with sol-gel electrodeposition at ITIES, ${ }^{21-23}$ as discussed hereafter.

Silica in-situ deposition at - or in the vicinity of - the ITIES has been achieved at the interface between water and dichloroethane by electrochemical transfer of trimethyloctadecylammonium cations from the organic phase to an aqueous solution containing a silica precursor. ${ }^{21} \mathrm{~A}$ second example includes the use of a nitrobenzene/water interface supported at solid electrode (so-called three phase junction) where electrochemical generation of protons was made to catalyze the condensation of n-octyltriethoxysilane present in nitrobenzene, resulting in the deposition of a silica film in the vicinity of three junction phase from aqueous side of the liquid/liquid interface. ${ }^{22}$ Recently, our group has proposed a simple route for the generation of porous silica at macroscopic liquid-liquid interfaces, based on the electrochemical transfer of cetyltrimethylammonium cations $\left(\mathrm{CTA}^{+}\right)$from an organic phase to an aqueous solution of hydrolyzed tetraethoxysilane (TEOS), and the characteristics of the silica deposits were shown to depend on the initial experimental conditions (template to precursor concentration ratio, composition of organic phase, etc.). ${ }^{23}$

In this report, we modified liquid-liquid interfaces of microscopic dimensions ( $\mu$ ITIES) by the ion transfer voltammetry method previously reported. ${ }^{21,23}$ Modification of $\mu$ ITIES offers the advantage of stabilizing mechanically the deposits for further analysis by physical chemistry techniques (scanning electron and Raman confocal microscopies, shear force profilometry and 
cyclic voltammetry). Scanning electron microscopy and shear force profilometry characterizations were correlated to the electrochemical measurements to investigate the impact of $\mathrm{CTA}^{+}$transfer on the deposit morphology. The silica deposits were analysed by Raman confocal microscopy to identify the different species present. Finally, template removal was performed by calcination and its effect on the film properties was studied by ion transfer voltammetry of tetraalkylammonium cations and confocal Raman spectroscopy.

\section{Materials and methods}

\subsection{Chemicals and reagents}

Most chemicals used here were commercially available: Bis(triphenylphosphoranyldiene) ammonium chloride, $\left(\mathrm{BTPPA}^{+} \mathrm{Cl}^{-}, 97 \%\right.$, Aldrich), potassium tetrakis(4-chlorophenylborate), $\left(\mathrm{K}^{+} \mathrm{TPBCl}^{-}, \geq 98 \%\right.$, Fluka), sodium chloride, $(\mathrm{NaCl}, \geq 98 \%$, Prolabo), cetyltrimethylammonium bromide (CTAB, $\geq 99 \%$, Acros Organics), tetraethoxysilane (TEOS, 98\%, Alfa Aesar), lithium chloride ( $\mathrm{LiCl}, \geq 99 \%$, Aldrich), tetramethylammonium chloride $\left(\mathrm{TMA}^{+} \mathrm{Cl}^{-}, \geq 99 \%\right.$, Fluka), tetrabuthylammonium chloride $\left(\mathrm{TBA}^{+} \mathrm{Cl}^{-}, \geq 99 \%\right.$, Fluka), ferric chloride hexahydrate $\left(\mathrm{FeCl}_{3} \cdot 6 \mathrm{H}_{2} \mathrm{O}\right.$, $99-102 \%$, Fluka), $\mathrm{HCl}$ (1M, volumetric solution, Riedel-de Haen), NaOH (pellets, pure, Riedel-de Haen), and 1.2-dichloroethane (DCE, $\geq 99 \%$, Sigma-Aldrich). All these chemicals were used as purchased. $\mathrm{BTPPA}^{+} \mathrm{Cl}^{-}$and $\mathrm{K}^{+} \mathrm{TPBCl}^{-}$were used to prepare the organic electrolyte by metathesis reaction (procedure of preparation reported elsewhere). ${ }^{23} \mathrm{NaCl}$ and $\mathrm{LiCl}$ were used as aqueous electrolytes, $\mathrm{CTAB}$ and $\mathrm{K}^{+} \mathrm{TPBCl}^{-}$were used to prepare the template salt (protocol of preparation reported elsewhere, ${ }^{23}$ ) and TEOS was used as silica precursor. Moreover $\mathrm{HCl}(1 \mathrm{M})$ and $\mathrm{NaOH}(1 \mathrm{M})$ were used to tune the $\mathrm{pH}$ of the aqueous phase to allow hydrolysis $(\mathrm{pH}=3)$ and condensation $(\mathrm{pH}=$ 9.5) of TEOS. The high density organic phase was a 1.2-dichloroethane (DCE) whereas the low density phase was $\mathrm{H}_{2} \mathrm{O}$ of high purity obtained from a Millipore milli-Q water purification system. The permeability of the $\mu$ ITIES before and after calcination was tested by ion transfer voltammetry using $\mathrm{TMA}^{+}$and $\mathrm{TBA}^{+}$as cationic probes. 


\subsection{Electrochemical setup}

The electrochemical cell was custom made and is presented in Fig. 1. The cell consists of a glass vessel covered by a lid with three holes. The side places were occupied by $\mathrm{Ag} / \mathrm{AgCl}$ reference and platinum mesh counter aqueous electrodes. We are using a 'four electrode' set-up where the organic reference electrodes also acts a counter electrode. This is possible because the surface area of the interface is relatively small compared to the size of the reference electrode. $\mathrm{The} \mathrm{Ag} / \mathrm{AgCl}$ reference electrode was prepared by oxidation of silver wire in oversaturated solution of $\mathrm{FeCl}_{3}$. The center hole was occupied by glassy capillary at the bottom of which a wafer supporting $\mu$ ITIES was fixed with silicone acetate sealant (Rubson ${ }^{\circledR}$ company). Before immersing the glassy capillary to the aqueous phase, it was filled with the organic phase and left for around one minute in order to impregnate the array of pores with the organic solution. Then, a silver wire was placed inside the capillary and the upper hole was covered with ParaFilm ${ }^{\circledR}$. The membrane used to support the $\mu$ ITIES is a $4 \times 4 \mathrm{~mm}^{2}$ membrane fabricated from a silicon wafer. The pores were patterned by UVphotolithography and pierced by a combination of wet and DRIE etches as described elsewhere. ${ }^{24}$ Figure 1 decribes schematically one of these membranes. The pore depth (d) and the pore diameter (ø) were maintained constant in this study and were $100 \mu \mathrm{m}$ and $10 \mu \mathrm{m}$ respectively. Four macroporous membranes with various pore center-to-center distances (spacing factor) and numbers of pores have been used, as listed in Table 1 .

Table 1. Characteristics of silicon membranes used to support $\mu$ ITIES.

\begin{tabular}{|c|c|c|c|c|}
\hline Design number & Radius / $\boldsymbol{\mu m}$ & Spacing / $\boldsymbol{\mu m}$ & Quantity of pores & Interfacial surface $\mathbf{a r e a}_{\mathbf{~} \mathbf{~} m^{2}}$ \\
\hline 1 & 5 & 20 & 2900 & $2.28 \times 10^{-3}$ \\
\hline 2 & 5 & 50 & 460 & $3.61 \times 10^{-4}$ \\
\hline 3 & 5 & 100 & 110 & $8.64 \times 10^{-5}$ \\
\hline 4 & 5 & 200 & 30 & $2.36 \times 10^{-5}$ \\
\hline
\end{tabular}


The electrochemical set-ups, depending on experimental condition, can be written as:

\section{Cell 1:}

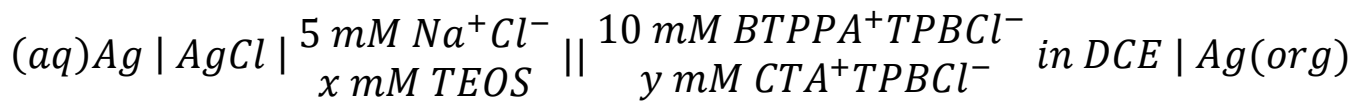

\section{Cell 2:}

(aq)Ag|AgCl| $\begin{gathered}10 \mathrm{mM} \mathrm{Li}^{+} \mathrm{Cl}^{-} \\ Z M \text { interfacial active ion }\end{gathered} \| 10 \mathrm{mM} \mathrm{BTPPA}^{+} \mathrm{TPBCl}^{-}$in $\mathrm{DCE} \mid \mathrm{Ag}(\mathrm{org})$

The cell 1 configuration was used for silica material deposition at $\mu$ ITIES. The various TEOS and $\mathrm{CTA}^{+}$concentrations used in the above mentioned cells were in the ranges $50 \mathrm{mM} \leq \mathrm{x} \leq 300 \mathrm{mM}$ and $1.5 \mathrm{mM} \leq \mathrm{y} \leq 14 \mathrm{mM}$, respectively. Silica deposition was mainly achieved by cyclic voltammetry but constant potential chronoamperometry $\left(\mathrm{E}_{\mathrm{appl}}=-0.15 \mathrm{~V}\right)$ was also used. $\mu$ ITIES modified with silica deposits were then tested in cell 2 via ion transfer voltammetry with interfacial active model ions (i.e., $\mathrm{TMA}^{+}$and $\mathrm{TBA}^{+}$). The fabrication process of the macroporous membranes leads to hydrophobic pore walls. ${ }^{24}$ The pores are therefore filled with organic phase, presenting an array of inlaid liquid-liquid micro-interface.

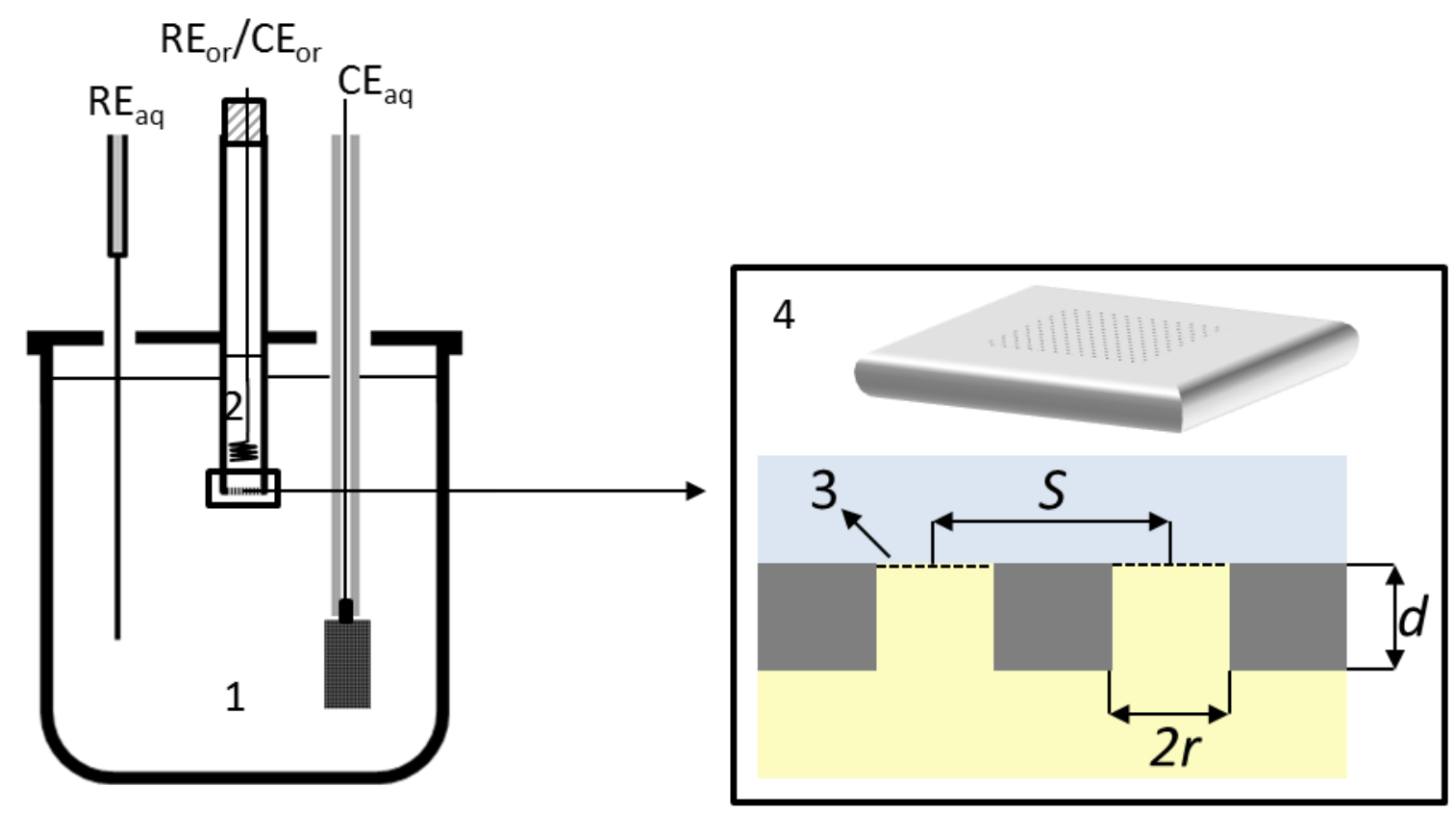


Figure 1. Schematic illustration of the electrochemical cell used in this study. Designation: 1 aqueous phase, 2 - organic phase, 3 - single $\mu$ ITIES, 4 - silicon membrane supporting $\mu$ ITIES $(r$ pore radius, $d$ - membrane thickness and $S$ - pore center-to-center distance).

\subsection{Instrumentation}

All electrochemical measurements were performed with a PGSTAT 302N with the four electrode cell described above. SEM images were obtained using a Philips XL30 microscope (with acceleration voltage equal to $1 \mathrm{kV}$ ), without any sample metallization. The initial observation of modified $\mu$ ITIES was made with an optical microscope NIKON 883315. Glass tips for profilometry based on shear force measurements were fabricated from borosilicate glass capillaries (O.D. 1.5 mm, I.D. $0.9 \mathrm{~mm}$ ) using vertical capillary puller. Prior to pulling, the capillaries were heated in the center and closed under vacuum. The tip diameter oscillates around $500 \mathrm{~nm}$. The software allowing the control of piezo positioning was custom written. Confocal Raman spectroscopy measurements were carried out with a Jobin Yvon T64000 spectrometer with green light laser (514 nm).

\section{Results and discussion}

\subsection{Silica formation at $\mu$ ITIES}

\subsubsection{Electrochemically assisted assembly of surfactant-templated silica}

The silica deposits were formed at the $\mu$ ITIES by cyclic voltammetry (CV) and a typical curve is shown in Fig.2. Cyclic voltammogram marked with solid line from Fig. 2 was recorded in cell 1 for $\left[\mathrm{CTA}^{+}\right]=14 \mathrm{mM}$ and $[\mathrm{TEOS}]=50 \mathrm{mM}$, and corresponds to interfacial silica deposits formation at the $\mu$ ITIES design number 3 (Table 1). 


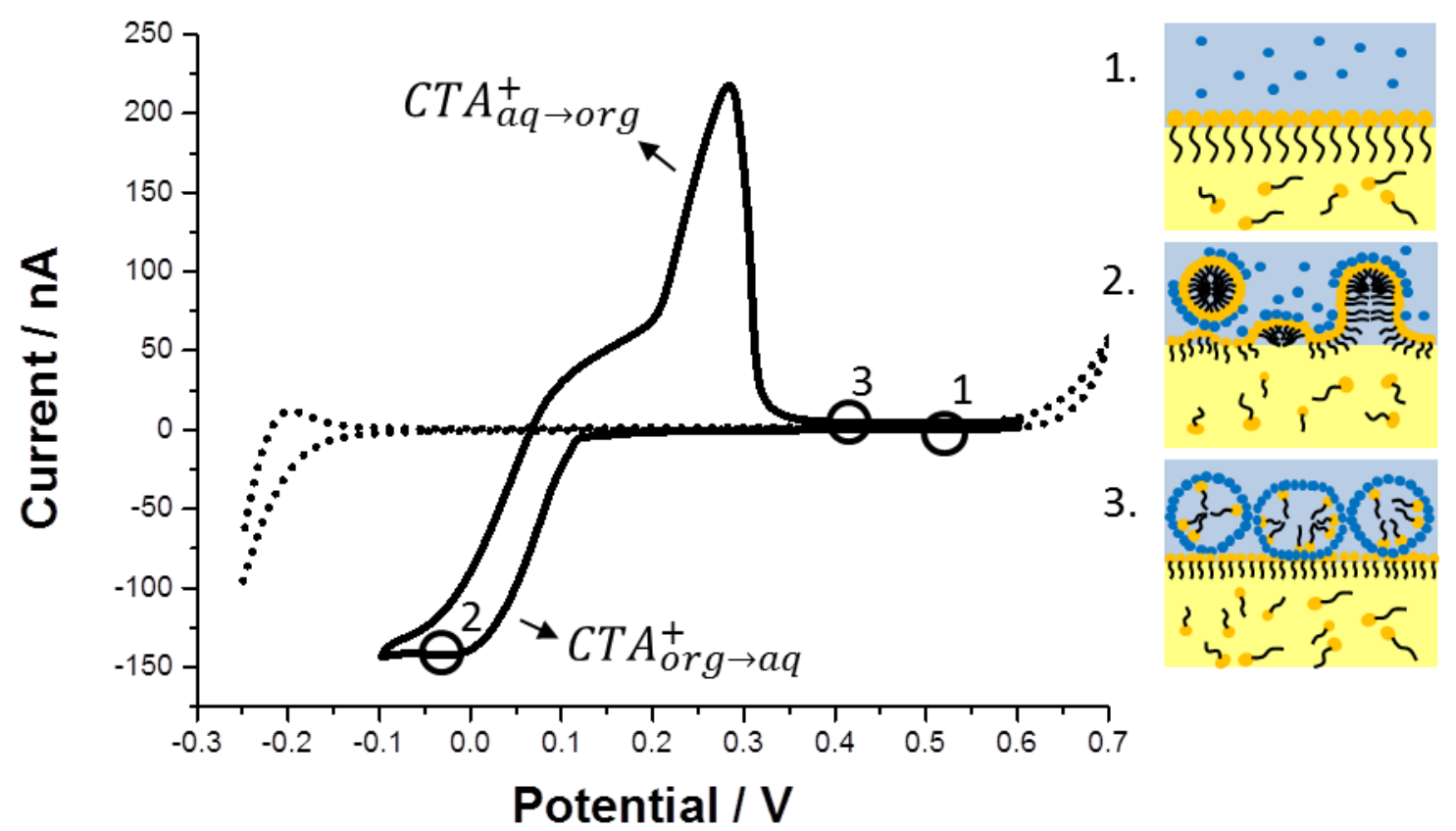

Figure 2. Typical cyclic voltammogram representing the formation of surfactant-templated silica material at $\mu$ ITIES (design number 3 ) recorded in cell 1 (solid line) for $[$ TEOS] $=50 \mathrm{mM}$ and $\left[\mathrm{CTA}^{+}\right]=14 \mathrm{mM}$. The pictures on the right correspond to the proposed mechanism for silica deposits formation at $\mu$ ITIES at distinct potential regions. Scan rate $=5 \mathrm{mV} \mathrm{s}^{-1}$. A blank cyclic voltammogram recorded in cell 2 (dotted line), without TEOS and $\mathrm{CTA}^{+}$in the medium, is also shown. Inset: Schematic representation of 1) hydrolyzed TEOS and $\mathrm{CTA}^{+}$ions in their respective phase at a positive potential: 2) Condensation of silica around assemblies of $\mathrm{CTA}^{+}$formed in the aqueous phase when negative potential is applied; 3) Silica deposits formed on the aqueous side of the interface with remaining $\mathrm{CTA}^{+}$on the aqueous side of the interface when positive potential is applied.

The dotted line on the same figure represents a blank curve recorded in cell 2 in the absence of precursor and template. Since the cationic template initially dissolved in the organic phase should 
be transferred to the aqueous phase to initiate the self-assembly condensation process, the interface was polarized from $+0.6 \mathrm{~V}$ to $-0.1 \mathrm{~V}$ during forward scan. We assumed that the interface at the beginning of polarization is covered with a monolayer of surfactant molecules (Fig. 2, scheme 1) and the small resulting current is only due to electrical double layer charging. At around $+0.1 \mathrm{~V}$, $\mathrm{CTA}^{+}$species start to transfer from the organic to the aqueous phase. The local concentration of $\mathrm{CTA}^{+}$transferred to the aqueous phase should exceed its critical micellar concentration (CMC), which is $1.4 \mathrm{mM}$ for $\mathrm{CTAB}$ in aqueous medium, ${ }^{25}$ to enable the formation of charged micelles. ${ }^{23}$ The presence of these micelles in the aqueous phase accelerates the condensation of the TEOS precursor around the surfactant template, resulting in interfacial silica material formation (Fig. 2, scheme 2). The negative signal of the CV curve is of sigmoidal shape (Fig. 2), which may suggest that the transfer of surfactant species across ITIES is not limited by linear diffusion (the origin of the curve shape will be discussed later). Forward scan was stopped at $-0.1 \mathrm{~V}$ because further negative polarization causes current increase due to background ion transfer $\left(\mathrm{Cl}^{-}\right.$transfer from aqueous to organic phase or $\mathrm{BTPPA}^{+}$transfer from organic to aqueous). On scan reversal, the inversed polarization of the interface induces the back transfer of $\mathrm{CTA}^{+}$species to the organic phase, resulting in a characteristic positive peak located at around $+0.26 \mathrm{~V}$ and terminated with an abrupt drop of current (i.e., no more $\mathrm{CTA}^{+}$species available for back transfer to the organic phase). This characteristic shape supports the presence of $\mathrm{CTA}^{+}$in the aqueous medium and within the silica gel network formed during the forward scan, and clearly indicates that the back transfer is not a diffusion-limited process. The $\mu$ ITIES is expected to be completely covered with the silica material after one cycle, as illustrated in Fig. 2 (scheme 3). This will be confirmed later on by SEM (see section 3.2).

\subsubsection{Factors affecting the electrochemical deposition process}

Both the limiting currents and the shape of current-potential curves are highly affected by the pore center-to-center distance, $S$, of the membrane support (Fig. 3). Actually, tuning the spacing 
factor (pores center-to-center distance) allows the control of planar and radial diffusion contributions governing the interfacial transfer of the active molecules. Davies and Compton ${ }^{26}$ divided microdisc arrays into four main groups based on their geometrical size with respect to the size of diffusion zones: (i) $\delta<\mathrm{r}, \delta<\mathrm{S}$; (ii) $\delta>\mathrm{r}, \delta<\mathrm{S}$; (iii) $\delta>\mathrm{r}, \delta>\mathrm{S}$ and (iv) $\delta>\mathrm{r}, \delta>>\mathrm{S}$, where $\mathrm{r}$ is the pore radius, $\mathrm{S}$ is the spacing factor and $\delta$ is the diffusion zone radius. For each group, they propose current response characteristics, which are as follows: (i) clear peak, (ii) steady state wave, (iii) slight peak to clear peak and (iv) clear peak, from which only group (ii) does not follow scan rate dependency. ${ }^{26}$ This terminology will be helpful to the description of CV data obtained here for the electrogeneration of silica films at $\mu$ ITIES. For the purpose of this study, we employed four different $\mu$ ITIES supporting membranes with constant pore radius $(5 \mu \mathrm{m})$ but various pore numbers and spacing factors (Table 1). Two distinct cases are reported in Fig. 3 where CV curves have been presented as current density versus potential variations to take into account the fact that the surface area of the array of pores supporting $\mu$ ITIES varies among each silicon wafer design. As shown, the increase in spacing from $20 \mu \mathrm{m}$ (solid line) up to $100 \mu \mathrm{m}$ (dashed line) led to dramatic increase in current densities along with significant change in the shape of the forward negative response, shifting from peak-like to wave-shaped. This can be explained by distinct diffusional regimes. Using the nomenclature proposed above, and based on shapes of current density - potential curves, one can attribute membrane number 1 to group (iii), whereas membrane number 3 belongs to borderline from groups (ii) and (iii). Since the small spacing (Fig. 3, c) give rise to slight peak, the condition $\delta>S$ has to be met. On the contrary, the steady-state wave indicates that $\delta<S$ in case of larger spacing (Fig. 3, b). As shown in supplementary information (Fig. SI1 a), membrane design number 2 gave rise to a wave with a slight-peak negative response, which means that $\delta$ is still larger than pore center-to-center distance. As expected, the CV response of membrane design number 4 was similar as membrane 3 (steady-state wave, as $S \gg>\delta$, Fig. SI1 b). The unaffected shape of the positive peak on scan reversal indicates a non-dependence on the type of diffusional regime, 
confirming that the reverse scan signals are not due to diffusion controlled processes. In addition, the larger current densities observed for wider spacing are explained by a radial diffusion process (i.e., as also observed for arrays of ultramicroelectrodes) ${ }^{27}$ whereas almost total overlap happens in case of pore center-to-center distances becoming of the same order of magnitude as the pore size and the resulting linear diffusion controlled processes led to lower currents passing across ITIES.
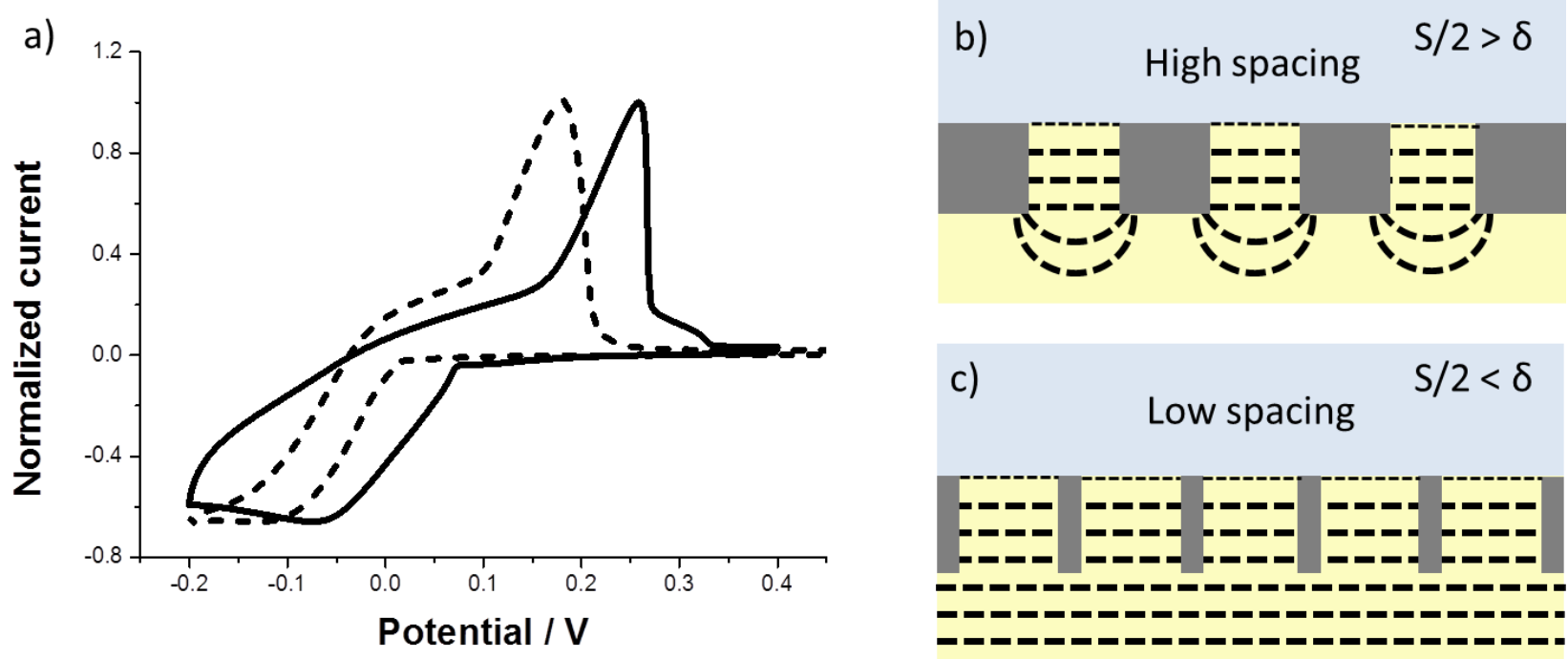

Figure 3. Variations of current density as a function of the applied potential for two different $\mu$ ITIES designs: number 1 (solid line) and number 3 (dashed line). The inset shows an enlargement of the voltammogram recorded at $\mu$ ITIES membrane design number 1 . Scan rate was $5 \mathrm{mV} \mathrm{s}^{-1}$ in both cases. Schematic views of the interfacial diffusion profiles at b) design 1 (high spacing, dotted line $\mathrm{CV}$ ) and c) design 3 (low spacing, solid line CV).

Fig. 4 (part a) illustrates the influence of the scan rate on the current-potential curves recorded during interfacial silica deposition at the membrane design number 3 . As shown, both the current intensity and shape of CV curves were found to vary, with negative signals evolving from slight peak to wave and to bigger peak when increasing the potential scan rate. These observations can be rationalized by analyzing the diffusion layer profile in each case. The diffusion coefficient was estimated by cyclic voltammetric studies at $0.95 \times 10^{-7} \mathrm{~cm}^{2} \mathrm{~s}^{-1}$. From such $D_{C T A^{+}}$values, one 
can estimate the diffusion layer thickness at various scan rates on the basis of the following equation (eq. 1): ${ }^{28,29}$

$$
\delta=\sqrt{2 D_{C T A^{+}} t}
$$

The resulting estimated thicknesses of diffusion layers of $\mathrm{CTA}^{+}$for each scan rate are thus roughly within the ranges: $630-930 \mu \mathrm{m}$ for $0.1 \mathrm{mV} \mathrm{s}^{-1}, 200-300 \mu \mathrm{m}$ for $1 \mathrm{mV} \mathrm{s}{ }^{-1}, 90-130 \mu \mathrm{m}$ for $5 \mathrm{mV}$ $\mathrm{s}^{-1}$, and $63-92 \mu \mathrm{m}$ for $10 \mathrm{mV} \mathrm{s}{ }^{-1}$.
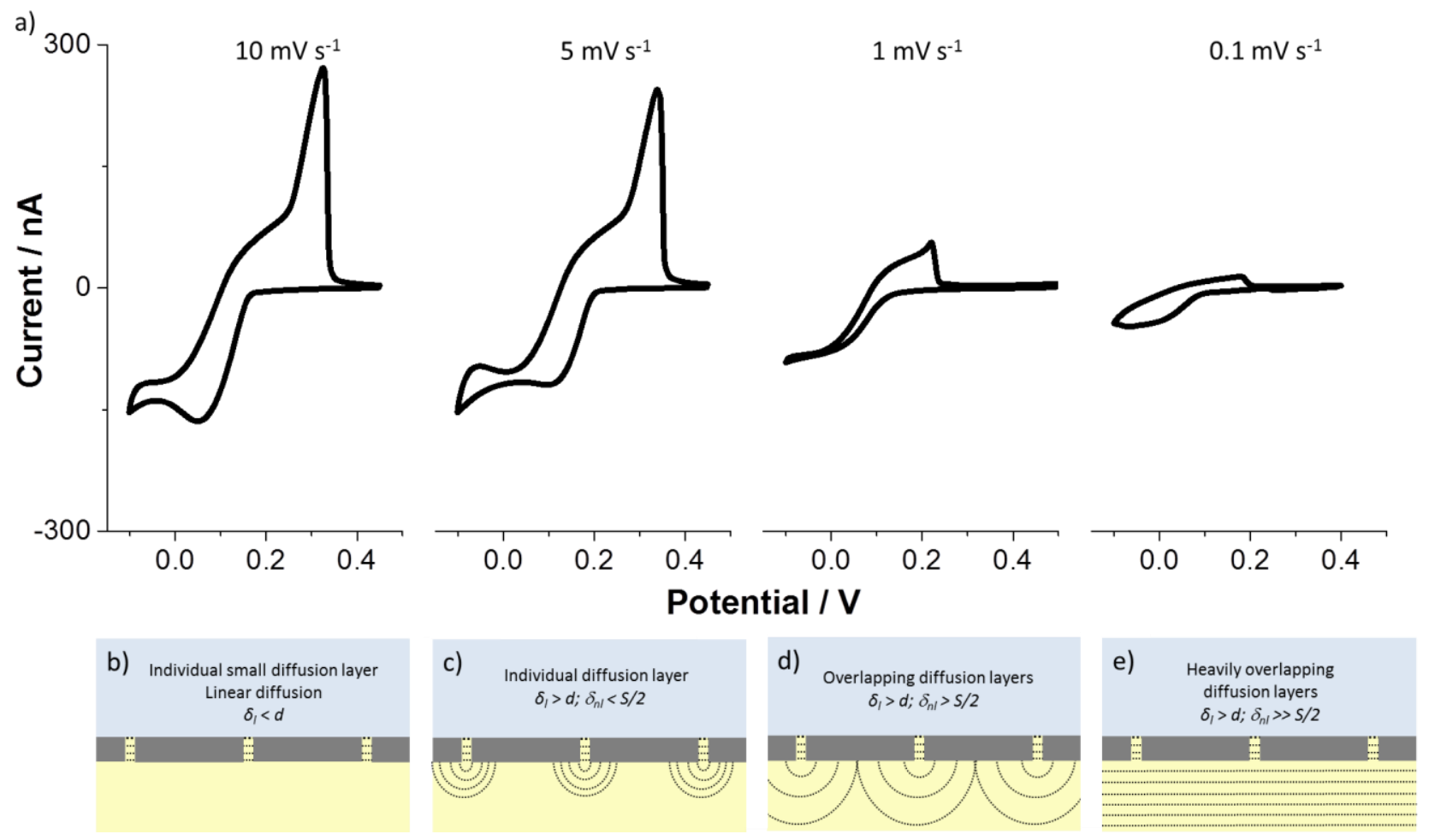

Figure 4. (a) Cyclic voltammograms recorded at various scan rates during interfacial silica deposits formation at $\mu$ ITIES number 3. (b-e) Schematic illustrations of diffusion layer profiles proposed for each scan rate: $10 \mathrm{mV} \mathrm{s}^{-1}(\mathrm{~b}) ; 5 \mathrm{mV} \mathrm{s}^{-1}(\mathrm{c}) ; 1 \mathrm{mV} \mathrm{s}^{-1}(\mathrm{~d})$ and $0.1 \mathrm{mV} \mathrm{s}^{-1}(\mathrm{e})$.

For the highest scan rate $-10 \mathrm{mV} \mathrm{s}^{-1}$ - the diffusion layer thickness, $\delta_{l}$, is less than the membrane thickness $-d=100 \mu \mathrm{m}-$ (see scheme $\mathrm{b}$ in Fig. 4) and hence the transfer inside the pore is limited only by linear diffusion ${ }^{30}$ (resulting in peak like response). In this case, not enough $\mathrm{CTA}^{+}$species 
are transferred from the organic to the aqueous phase and no silica film formation was observed (as checked by profilometry based on shear force measurements). All the amount of $\mathrm{CTA}^{+}$species transferred to the aqueous phase on forward scan are transferred back to the organic medium on scan reversal, as supported by forward and reverse charge transfer of similar magnitude (Figure SI2). Decreasing potential scan rates down to 5 and $1 \mathrm{mV} \mathrm{s}^{-1}$ led to diffusion layer thicknesses increasing from slightly larger (i.e., $90-130 \mu \mathrm{m}$ for $5 \mathrm{mV} \mathrm{s}^{-1}$ ) to much larger (i.e., $200-300 \mu \mathrm{m}$ for $1 \mathrm{mV} \mathrm{s}^{-1}$ ) than the membrane thickness, leading to sigmoidal-shaped current responses on forward scan (yet with an additional residual and very slight peak at $5 \mathrm{mV} \mathrm{s}^{-1}$ ). Such wave found its origin from the prolongation in diffusion layers profiles (forming hemispherical diffusion zones at the pores entrance due to fulfilling of $S / 2>\delta_{n l}$ conditions, see schemes c and $\mathrm{d}$ in Fig. 4). In addition, the local changes in the interfacial properties as a result of growing silica deposit also play a role in the evolution of $\mathrm{CV}$ curves, as one can expect some additional resistance to mass transport through the interface in the presence of a silica film. This is notably the case of $1 \mathrm{mV} \mathrm{s} \mathrm{s}^{-1} \mathrm{scan}$ rate (see scheme d in Fig. 4) for which long experimental time would cause an increase in $\delta_{n l}$ exceeding half of pore center-to-center distance $(S / 2)$ on the basis of the estimated $\delta$ values (i.e., $200-300 \mu \mathrm{m}$ in this case), leading to an expected overlap of radial diffusion zones, which should have given rise to a peak-like response. The fact that a sigmoidal response was obtained here is attributed to the restricted transfer of $\mathrm{CTA}^{+}$across the interfacial synthesized silica material (apparent diffusion values for the overall process lower than those in solution at an unmodified liquid-liquid interface). Actually, much longer experimental times were necessary (for instance, that corresponding to a potential scan rate as low as $0.1 \mathrm{mV} \mathrm{s}^{-1}$ ) to get conditions of total diffusion overlap (see scheme e in Fig. 4). In this case, the $C T A_{\text {org } \rightarrow a q}^{+}$transfer is limited by linear diffusion above the pores, which becomes the limiting factor, leading to a peak-shaped voltammogram. The large difference between the charge passed through the $\mu$ ITIES during forward and reverse scan indicates that a significant part of $\mathrm{CTA}^{+}$species transferred to the aqueous phase has been involved in the formation of silica 
deposits, as trapped inside the mesostructure, and thus no more available for back transfer to the organic phase on scan reversal (Figure SI2).

The interfacial silica formation is possible only when $\mathrm{CTA}^{+}$is present in the organic phase and hydrolyzed TEOS in the aqueous phase. The driving force of the process is the electrochemicallyassisted transfer of $\mathrm{CTA}^{+}$species from the organic to the aqueous medium where self-assembly condensation occurs. Therefore, the composition of both media is likely to affect the deposition process. To check this, we have chosen deposition conditions corresponding to pores behaving independently of each other (i.e. avoiding overlap of radial diffusion layers), which is achieved for membrane design number $3(100 \mu \mathrm{m}$ pore center-to-center distance) and a moderate potential scan rate $(5 \mathrm{mV} / \mathrm{s})$. The results are depicted in Supporting Information (Fig. SI3). When maintaining [TEOS] at a constant value in the aqueous phase and varying $\left[\mathrm{CTA}^{+}\right]$from $1.5 \mathrm{mM}$ up to $14 \mathrm{mM}$ in the organic phase, continuous increase in negative currents was observed due to enhanced $C T A_{\text {org } \rightarrow a q}^{+}$transfer. This reaction is the rate-determining step. On scan reversal, the backward transfer peak increased first with $\left[\mathrm{CTA}^{+}\right]$(up to $3 \mathrm{mM}$ ) and then tended to level off for higher $\mathrm{CTA}^{+}$ concentrations (see graph a in Fig. SI3). This trend can be explained by the formation of the surfactant-templated silica deposits at the interface: for low $\left[\mathrm{CTA}^{+}\right]$, most $\mathrm{CTA}^{+}$species are incorporated into the film and are thus no more available for back transfer, whereas higher $\left[\mathrm{CTA}^{+}\right]$ values led to the formation of much thicker silica deposits which starts to act as a physical barrier to the back transfer reaction. On the other hand, no significant changes neither in current intensity nor in $\mathrm{CV}$ curve shape was noticed when keeping $\left[\mathrm{CTA}^{+}\right]$constant and rising [TEOS] from 50 to 300 $\mathrm{mM}$ (see graph $\mathrm{b}$ in Fig. SI3). The only difference was a potential shift of the whole CV curve to the positive direction, indicating an easier $C T A_{o r g \rightarrow a q}^{+}$transfer, which is explained by enhanced interactions between the transferring $\mathrm{CTA}^{+}$cations with the more concentrated negatively-charged silica species in the aqueous phase. These results confirm that the driving force (and limiting factor) of the deposition process are governed by the amount of $\mathrm{CTA}^{+}$species transferring to the aqueous 
phase where film formation occurs, and that TEOS concentration does not constitute a ratedetermining factor, on the contrary to what was reported for electro-assisted self-assembly of mesoporous silica films on solid electrodes, ${ }^{15,14}$ because of different deposition mechanism. This qualitative discussion is based on a rather simple micro-interface array model and is supported by the following morphological study.

\subsection{Morphological study}

Morphology of the silica deposits generated at $\mu$ ITIES under various conditions was analyzed by SEM and profilometry (based on shearing force measurement), and illustrative results are shown on Fig. 5. They concern deposits generated using the same composition of solutions $\left([\mathrm{TEOS}]_{\mathrm{aq}}=50\right.$ $\mathrm{mM}$ and $\left.\left[\mathrm{CTA}^{+}\right]_{\text {org }}=14 \mathrm{mM}\right)$, but on the basis of different supporting silicon membranes and distinct deposition conditions (potential scan rates and number of cycles). The data are presented under the form of tilted views of single pore (row a) and pore arrays (row b), as well as 3D mapping profilometry while keeping constant the $\mathrm{z}$ axis scale in all cases (row c). The silica deposits are always formed on the aqueous side of the liquid/liquid interface (i.e. on the top of the macroporous silicon membrane). A second point is the good quality of the deposits, which have been formed uniformly on all pores, and their crack-free appearance after surfactant removal (images were recorded after calcination at $400^{\circ} \mathrm{C}$ ) suggests a good mechanical stability. When using the same support ( $\mu$ ITIES number 2), keeping constant the potential scan rate (at $5 \mathrm{mV} \mathrm{s}^{-1}$ ), but increasing the number of cycles from half scan (first column) to 3 scans (second column), one can notice an increase in both the deposit height (from $1.7 \mu \mathrm{m}$ to $3.4 \mu \mathrm{m}$ ) and the deposit diameter (from $14 \mu \mathrm{m}$ to $15.7 \mu \mathrm{m}$ ), with some more pronounced curvature of the top surface of the deposits. Also, there was no significant difference in the deposit diameter between samples prepared from half and whole potential cycle, showing only an increase in the deposit height from $1.7 \mu \mathrm{m}$ up to $2.7 \mu \mathrm{m}$, consistent with longer duration of negative potentials application. All these results confirm that the electrochemically-induced $C T A_{\text {org } \rightarrow a q}^{+}$transfer is indeed at the origin of the surfactant-templated 
silica self-assembly process. Control experiments showed that the condensation of silica does not occur in the absence of surfactant. ${ }^{23}$
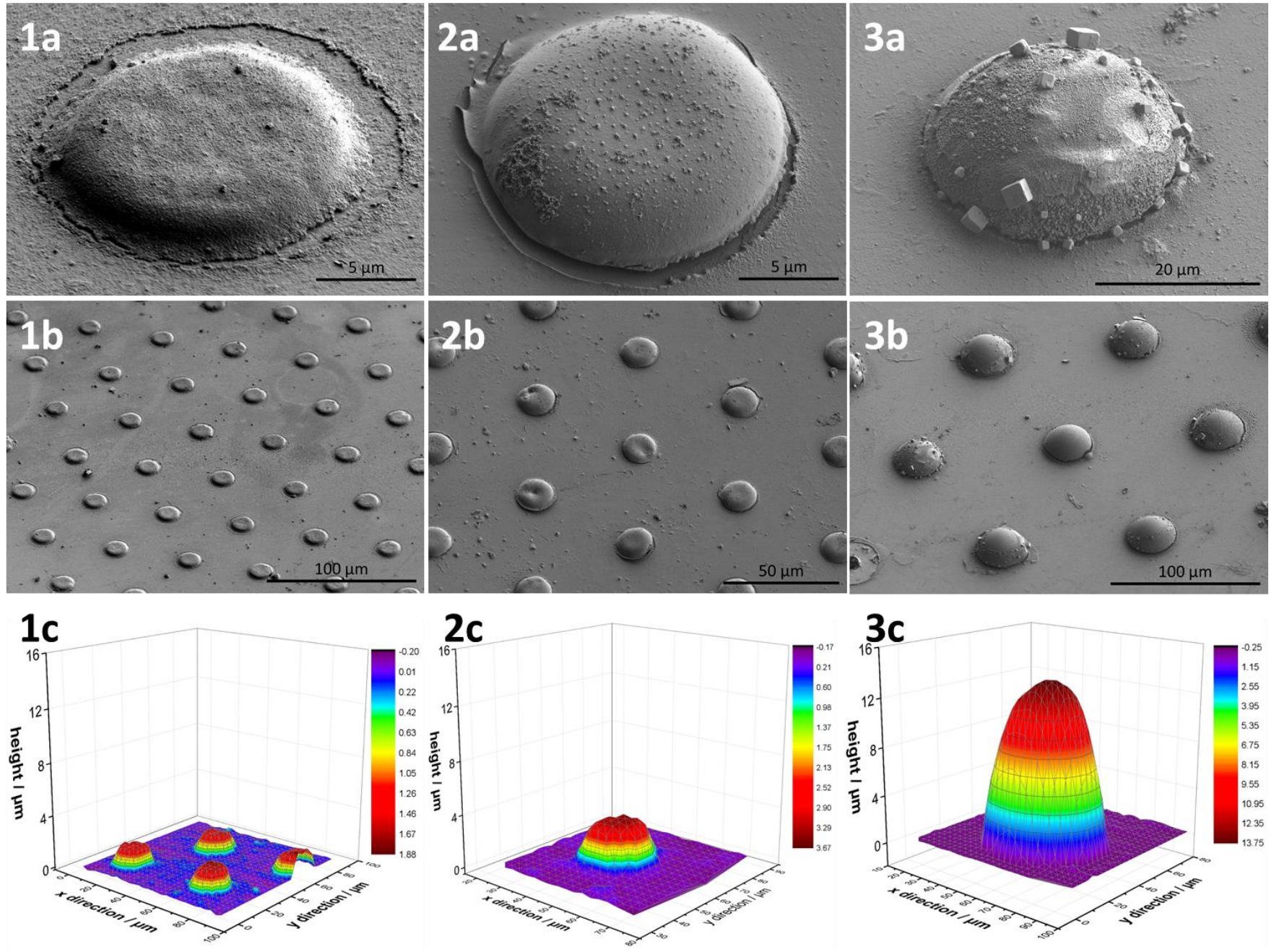

Figure 5. SEM micrographs and 3D profilometry mapping based on shear force measurements obtained for various $\mu$ ITIES modified with silica deposits. The rows correspond to three different points of views: (a) side view on single pore recorded by SEM, (b) side view on array of modified interfaces recorded by SEM and (c) modified interface mapping made by profilometry. The columns divide the images depending on synthesis initial conditions: (1) deposits prepared by one linear scan voltammetry (half $\mathrm{CV}$ scan) at $5 \mathrm{mV} / \mathrm{s}$ using $\mu$ ITIES number 2; (2) deposits prepared by three successive $\mathrm{CV}$ scans at $5 \mathrm{mV} \mathrm{s}^{-1}$ using $\mu$ ITIES number 2; and (3) deposits prepared by one CV scan at $0.1 \mathrm{mV} \mathrm{s}^{-1}$ using $\mu$ ITIES number 3 . 
However, the deposit height growth was not directly proportional to the number of CV cycles, most probably due to enhanced resistance to $C T A_{\text {org } \rightarrow a q}^{+}$transfer in the presence of much thicker deposits. A more effective way to get massive silica material deposition at the $\mu$ ITIES is to slow down the potential scan rate (which also requires the use of a silicon membrane with larger pore spacing to avoid overlap of the radial diffusion profiles). This is shown on part 3 of Fig. 5 for the modification of membrane design number 3 by one scan at $0.1 \mathrm{mV} \mathrm{s}^{-1}$, leading to much thicker deposits (13.1 $\mu \mathrm{m}$ height and $33.1 \mu \mathrm{m}$ diameter). Since the generated deposits are massive comparing to other experiments, they are likely to be more affected by calcination and can suffer from some losses (see, e.g., one deposit missing on the bottom left of part $3 b$ in Fig. 5).

Another way to control the generation of silica deposits is the use of constant-potential amperometry (i.e., chronoamperometry) instead of linear sweep or cyclic voltammetry. Too short experiment times $(5-10 \mathrm{~s})$ did not lead to any silica material formation. Then, the amount of deposited material was found, as expected, to increase with the amperometry duration (for example $50 \mathrm{~s}$ deposition time led to deposits with $3.7 \mu \mathrm{m}$ in height and $14.9 \mu \mathrm{m}$ in diameter), while extending the electrosynthesis up to $200 \mathrm{~s}$ enabled the formation of massive deposits, with $8.4 \mu \mathrm{m}$ in height and $18.6 \mu \mathrm{m}$ in diameter. As for deposits prepared by cyclic voltammetry, their shape was also found to change from rather flat to hemispherical when increasing the charge passing across the interface contributing thereby to larger amounts of silica material deposited at the $\mu$ ITIES. Finally, the variation in shape of the silica deposits resembles to an image of the evolution of the diffusion layer profiles: short deposition times corresponds to mainly linear diffusion limitations, yet with some radial contribution at the macropore edges, while longer experiments are governed by radial diffusion control (Figure 6), where the deposit height, $h$, was plotted as function of the difference between deposit and pore radii, $r_{d^{-}} r_{p}$. In the beginning of the deposition process, $h \approx r_{d^{-}}$ $r_{p}$, corresponding to a rather flat morphology, while subsequent growing led to more hemispherical shape with $h$ values likely to rise up to $2 \times\left(r_{d^{-}} r_{p}\right)$. Finally, more massive deposits were characterized 
by preferential lateral growth $\left(h<2 \times\left(r_{d}-r_{p}\right)\right)$. Under the conditions presented here, the displacement of liquid/liquid micro-interfaces under charge $\operatorname{transfer}^{31}$ does not seem to be an issue. Indeed, SEM images for detached membranes (see Fig. SI4 in Supporting Information) suggest that the silica deposits are filled inside and rather flat at the bottom.
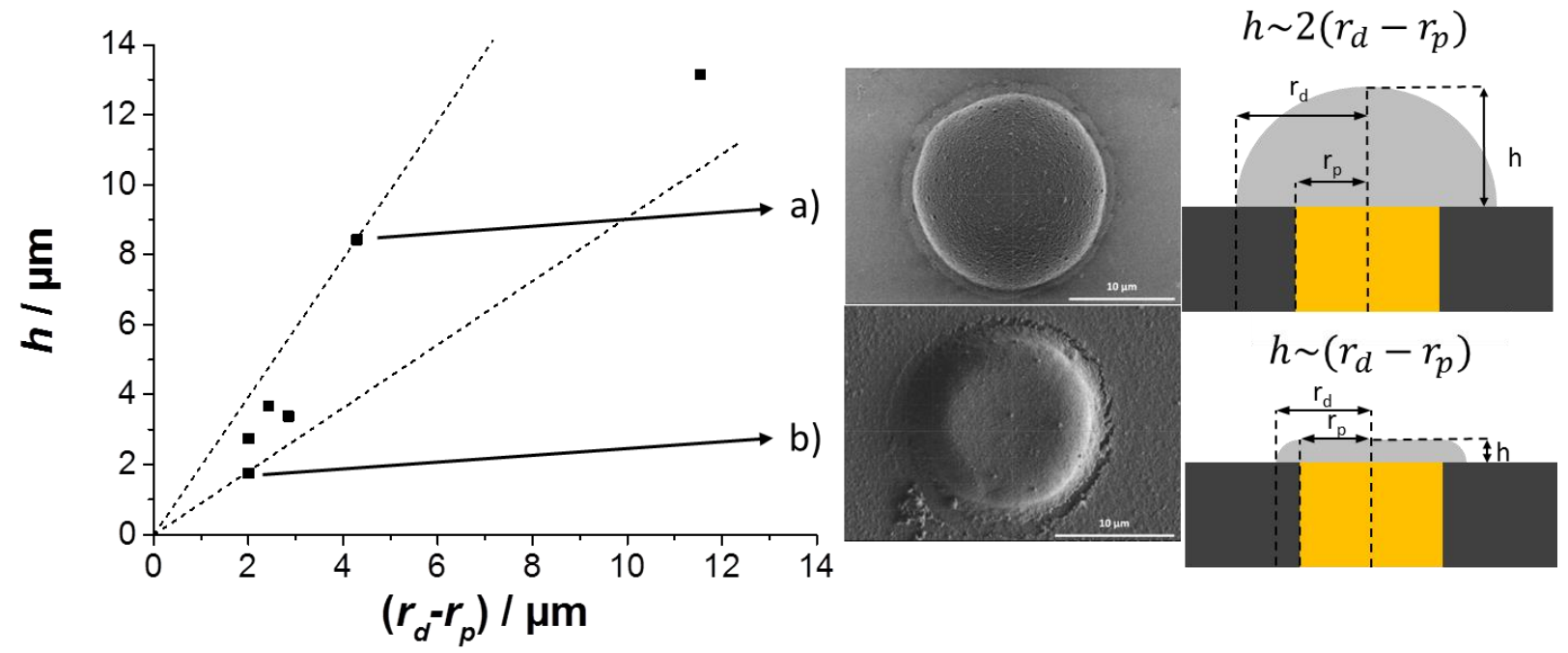

Figure 6. Deposit height versus the difference between deposit and pore radii for materials prepared either by cyclic voltammetry or chronoamperometry. Two "extreme" cases are also illustrated on the right part of the figure (SEM micrographs and corresponding schemes), showing deposits synthesized with a) chronoamperometry $(E=-0.15 \mathrm{~V}, \mathrm{t}=200 \mathrm{~s}$, membrane design number 4) and $\mathrm{b})$ cyclic voltammetry $(5 \mathrm{mV} / \mathrm{s}$, half cycle, membrane design number 3$)$.

Another point, yet minor, to mention from the morphological analysis is the presence of cubes on some silica deposits (see, e.g., image 3a in Fig. 5), which are $\mathrm{NaCl}$ crystals arising from residual background electrolyte back transfer from organic to aqueous phase. This phenomenon is similar to that reported by Silver et al. $^{32}$, on the basis of protein crystallization experiments at liquid/liquid interfaces. We thus anticipate that the present electro-assisted generation of silica material could be also suitable to the entrapment of proteins in the silica matrix (sol-gel silica is indeed known to enable encapsulation of proteins ${ }^{33}$ ) as an effective way to immobilize biomolecules at liquid/liquid 
interfaces. Finally, a very thin additional silica layer covering the whole silicon membrane + silica deposits can be also evidenced from SEM pictures (see micrographs 1a and 2a in Fig. 5). This arises most probably from some evaporation induced condensation of TEOS and silica deposition even if each electrosynthesis experiment was followed by careful rinsing with distilled water.

\subsection{Spectroscopic and electrochemical characterization of the deposits}

Confocal Raman spectroscopy was first used to show the formation of a silica network at $\mu$ ITIES. It has been performed after thermal treatment of the deposits $\left(24 \mathrm{~h}\right.$ storage at $130^{\circ} \mathrm{C}$ followed by $30 \mathrm{~min}$ at $400^{\circ} \mathrm{C}$ ) to be able to detect the characteristic lines of silica without being disturbed by huge signals arising from the organic matter expected to be present in the same spectral region (see a typical spectrum on Fig. SI5 in Supporting Information). In addition to the narrow and intense band at $520 \mathrm{~cm}^{-1}$ due to the vibration mode characteristic of the silicon wafer support, one can notice a broad band from $375 \mathrm{~cm}^{-1}$ to $500 \mathrm{~cm}^{-1}$ attributed to the $\mathrm{Si}-\mathrm{O}-\mathrm{Si}$ vibrational mode, and a single band at $793 \mathrm{~cm}^{-1}$ suggesting the presence of terminal $\mathrm{Si}-\mathrm{OH}$ groups. This strongly supports the formation of silica. Raman spectroscopy can be also used to characterize the organic species that have been incorporated into the silica material during the deposits formation, as well as to check the effectiveness of their removal upon calcination. This is shown on Fig. $7 \mathrm{~b}$, where the broad and intense signal located in the region $2760-3020 \mathrm{~cm}^{-1}$ region, corresponding to the $-\mathrm{CH}_{2}-$ stretching mode of the long alkyl chain of $\mathrm{CTA}^{+}$species,${ }^{34}$ confirms the presence of the surfactant template in the material. This signal almost disappears after heat treatment, indicating the successful removal of the organic template. From Fig. 7b, one can also notice a signal of small to medium intensity at $3060 \mathrm{~cm}^{-1}$, which can be ascribed to the $\mathrm{C}-\mathrm{H}$ stretching mode of aromatic rings, which are present in the organic electrolyte $\left(\mathrm{BTPPA}^{+} \mathrm{TPBCl}^{-}\right)$, suggesting that some of these ions have been co-encapsulated in the silica material in addition to the surfactant template. This is best shown on Fig. 7a, where the typical signature of $\mathrm{BTPPA}^{+} \mathrm{TPBCl}^{-}$is seen via the bands located in the 600 to $1800 \mathrm{~cm}^{-1}$ region ${ }^{35}$ (for instance the peak at around 1000 
$\mathrm{cm}^{-1}$ is due to the vibration of the aromatic ring $\left.{ }^{36}\right)$. After calcination, all these bands disappeared, which indicates the complete removal of this organic electrolyte from the deposits. One can also notice from Fig. 7a two broad peaks of weak intensity in the region from 1250 to $1750 \mathrm{~cm}^{-1}$, which appeared upon calcination, representing actually the D and $\mathrm{G}$ bands of traces of amorphous carbon arising from thermal decomposition of the organic molecules. ${ }^{37}$ These results support that the mesopore channels have been liberated from most of their organic content, even if the quantitative analysis of the porosity by the classical gas adsorption method was not possible due to the too low amount of available material (too small deposits). For the same reason, the observation of the mesostructure by transmission electron microcopy was not achieved, but one can reasonably assumed that it corresponds to the same wormlike structure as that reported for similar electroassisted deposition of larger amounts of material at macroscopic liquid/liquid interfaces. ${ }^{23}$
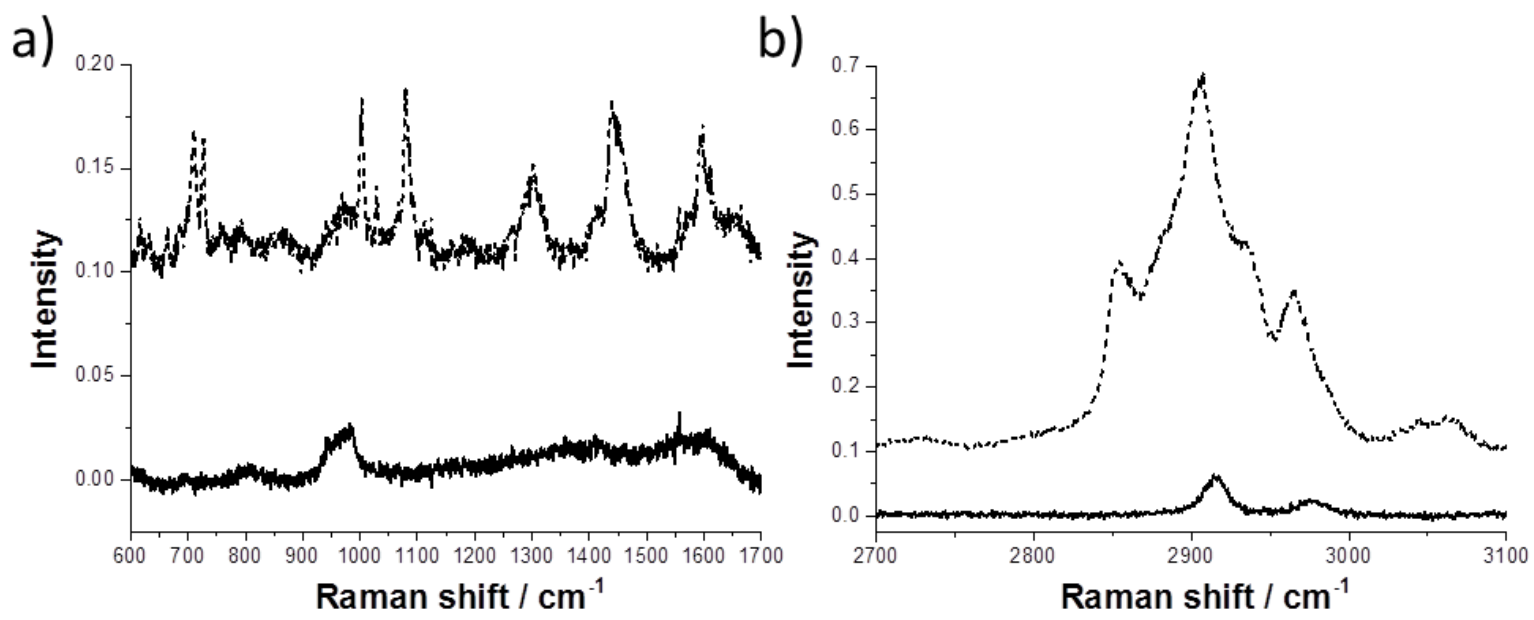

Figure 7. Typical RAMAN spectra recorded for an electrogenerated silica deposit in two distinct vibrational ranges (a,b), respectively before (dashed line, a) and after (solid line, b) calcination.

The deposits were then characterized by cyclic voltammetry data (Fig. 8). Silica deposits employed here were obtained by $\mathrm{CV}$ in the following conditions: $\left.[\mathrm{TEOS}]_{\mathrm{aq}}=50 \mathrm{mM} ; \mathrm{CTA}^{+}\right]_{\text {org }}=$ $14 \mathrm{mM}$; potential scan rate $5 \mathrm{mV} \mathrm{s}^{-1} ; 2$ subsequent cycles at the membrane design number 3 , and then, calcinated at $400^{\circ} \mathrm{C}$ after $24 \mathrm{~h}$ storage at $130^{\circ} \mathrm{C}$. The cyclic voltammogram recorded in a blank 
electrolyte for $\mu$ ITIES with silica deposits before calcination (Fig. 8Aa) is characterized by a high capacitive contribution, which is significantly lower after heat treatment (Fig. 8Ab), suggesting an effect of the removal of organic species from the silica material. This is also evidenced by the appearance of a broad signal in the region of $\mathrm{Cl}_{a q \rightarrow o r g}^{-}{ }^{38}$, indicating possible interfacial transfer through the silica film after template removal.

A
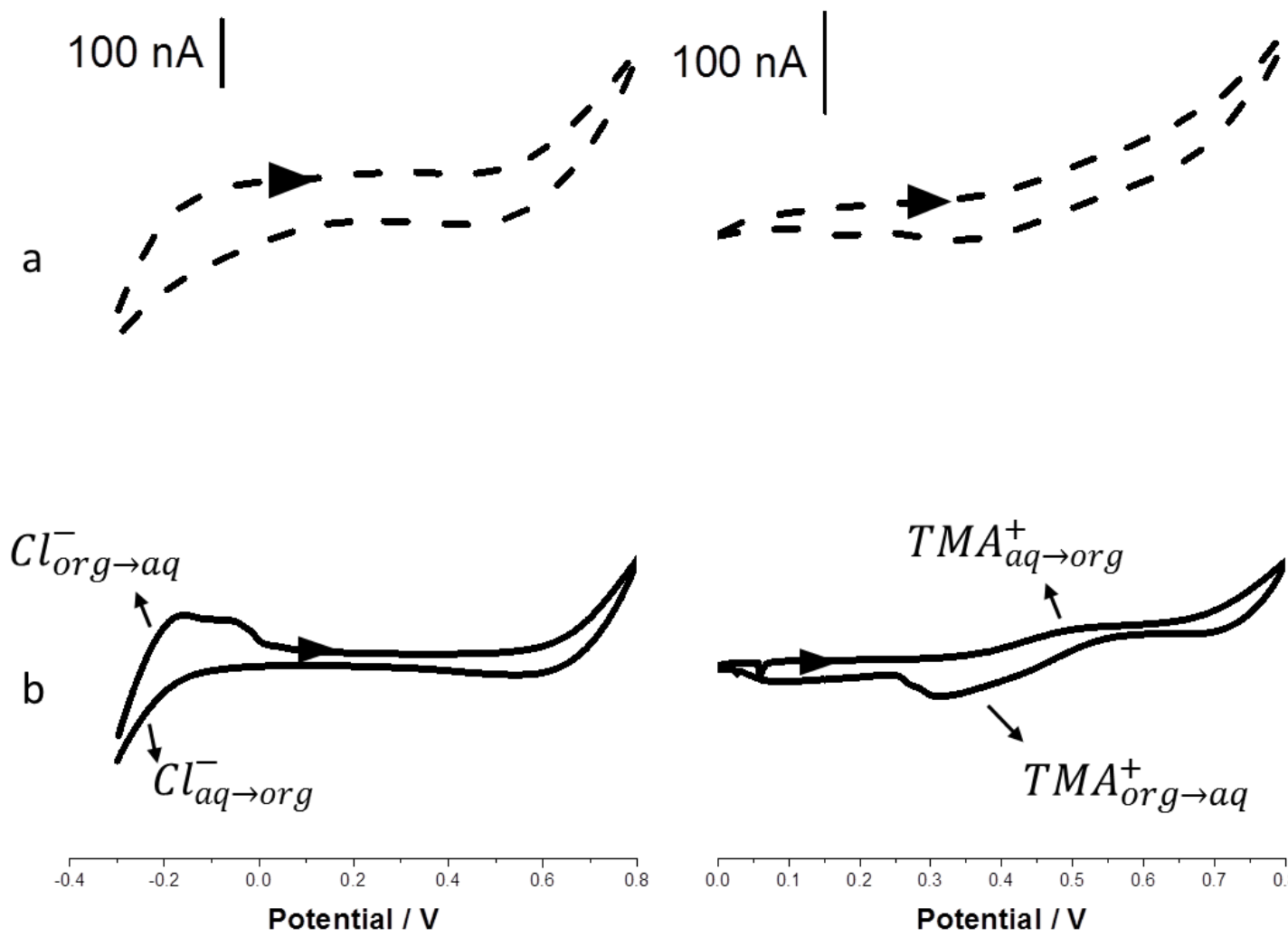

B

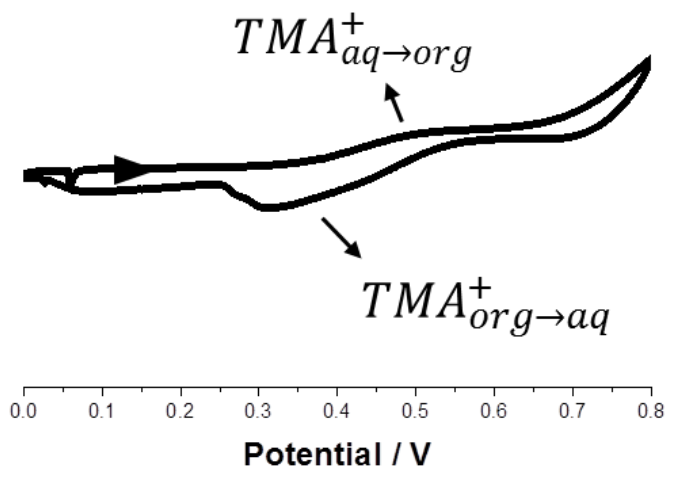

Figure 8. $\mathrm{CV}$ curves recorded in a blank electrolyte (A) or $70.9 \mu \mathrm{M} \mathrm{TMA}^{+}$(B), using $\mu$ ITIES number 3 modified with silica deposits, respectively before (a) and after calcination (b). Silica deposits were formed by $\mathrm{CV}\left(2\right.$ cycles at $5 \mathrm{mV} \mathrm{s}^{-1},\left[\mathrm{CTA}^{+}\right]=14 \mathrm{mM}$ and $\left.[\mathrm{TEOS}]=300 \mathrm{mM}\right)$.

In order to better evaluate the permeability of $\mu$ ITIES modified with silica deposits before and after calcination, we employed model interfacial active cations. As shown with $\mathrm{TMA}^{+}$(Fig. 8B), the transfer of $T M A_{a q \rightarrow \text { org }}^{+}$through the $\mu$ ITIES modified with the silica deposits was clearly observed 
after removal of the surfactant template (Fig. 8Bb), confirming good permeability of the mesoporous film, whereas $\mathrm{TMA}^{+}$transfer was either negligible or masked by the large capacitive current, which occurred before calcination (Fig. 8Ba). The corresponding CV curve was characterized by a sigmoidal wave when transferring from aqueous to organic phase and a peak-like response on scan reversal (due to the restricted amount of $\mathrm{TMA}^{+}$for back transfer). The absence of significant $T M A_{a q \rightarrow o r g}^{+}$transfer prior to template removal also confirms the good quality of the deposits and the fact that all - or the greatest part of - the macropores of the silicon membrane have been successfully modified with the silica deposits.

Although a bulky model cations such as $\mathrm{TBA}^{+}$(hydrodynamic radii equal to $0.48 \mathrm{~nm}^{39}$ ) is used, apparent high rates of mass transport through the mesoporous silica films are obtained after template removal. This is shown in Fig. 9 for the $\mu$ ITIES design number 4 (i.e., with the largest macropores spacing). The macropores coverage with silica deposits was $100 \%$ (i.e., no pores without silica), as controlled by optical microscopy. Fig. 9 (a) compares the transfer of $\mathrm{TBA}^{+}$across the bare $\mu$ ITIES and the silica modified membrane, as recorded in cell 2 containing $56.8 \mu \mathrm{M} \mathrm{TBA}^{+}$. As shown, the transfer reaction $T B A_{a q \rightarrow \text { org }}^{+}$was characterized by an positive wave in both cases, with a small drop (by ca. 10\%) which was noticed in the presence of silica deposits with respect to the unmodified $\mu$ ITIES, while the half-wave potential shifted from $+0.015 \mathrm{~V}$ to $+0.025 \mathrm{~V}$. The very small decrease in intensity indicates very few resistance to mass transport of $\mathrm{TBA}^{+}$species through the mesoporous silica material deposited at the $\mu$ ITIES, which is also consistent with the rather fast mass transport rates reported for solid electrodes modified with mesoporous silica particles ${ }^{40}$ or thin films. ${ }^{14,41}$ 


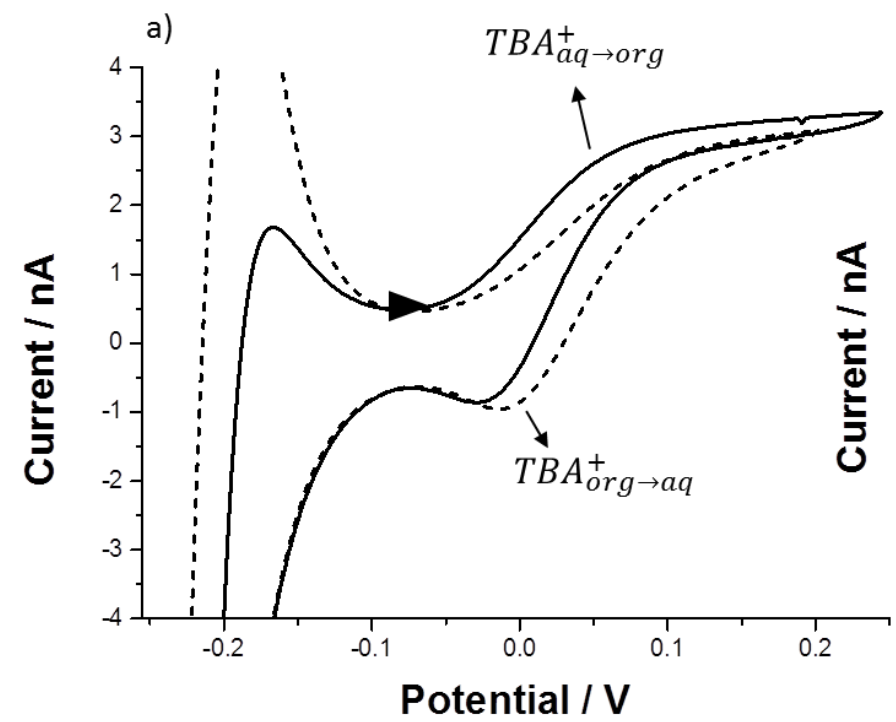

b)

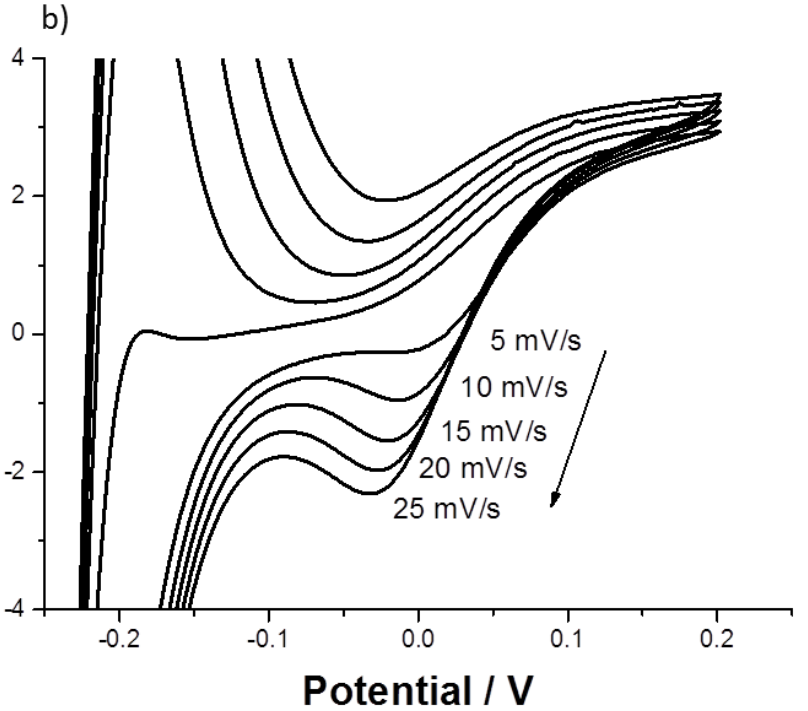

Figure 9. a) Cyclic voltammograms showing the transfer of $\mathrm{TBA}^{+}$across the unmodified $\mu$ ITIES (solid line) and the mesoporous silica modified $\mu$ ITIES (dashed line), as recorded at $10 \mathrm{mV} / \mathrm{s}$ from an aqueous solution containing $56.8 \mu \mathrm{M} \mathrm{TBA}^{+}$. b) Scan rate dependency for $\mathrm{TBA}^{+}$transfer across the silica deposits modified $\mu$ ITIES. The $\mu$ ITIES design was number 4 and silica deposition was made by $\mathrm{CV}\left(1\right.$ cycle at $\left.5 \mathrm{mV} \mathrm{s}^{-1}\right)$, from $[\mathrm{TEOS}]_{\mathrm{aq}}=50 \mathrm{mM}$ and $\left[\mathrm{CTA}^{+}\right]_{\mathrm{org}}=14 \mathrm{mM}$.

The above observations of possible and fast ion transfer across $\mu$ ITIES modified with mesoporous silica are promising for analytical applications, by taking advantage of the high sensitivity of the microscopic interfaces combined to fast transport of the analytes through the silica film modifier. Moreover, the selectivity of the detection could be manipulated by tuning the interactions between the analyte and the mesoporous silica deposits, which would be achievable by suitable functionalization of the silica walls (for instance by tuning the hydrophobic-to-hydrophilic balance $^{42}$ or by attaching selected organo-functional groups ${ }^{41,43}$ ).

A final point to stress is related to the geometrical surface of $\mu$ ITIES that is likely to change upon modification with the hemispherical deposits oriented towards the aqueous phase, the surface of which being expected to be greater than the area of flat $\mu$ ITIES supported by array of unmodified 
pores, and hence the diffusion layer profile of single $\mu$ ITIES should increase upon modification. Fig. 9 (b) shows the scan rate dependency for TBA $^{+}$transfer across the $\mu$ ITIES supported with silica deposits. Since the positive current remains sigmoidal in shape and its intensity remains relatively constant among each scan rate, one can conclude that the $\mathrm{TBA}^{+}$transferring process from aqueous to organic phase remains controlled by radial diffusion, without overlap of diffusion layers, keeping the $T B A_{a q \rightarrow \text { org }}^{+}$reaction similar to that of an ensemble of ultramicroelectrodes, with the same advantages in terms of sensitivity. The shape of $\mathrm{TBA}^{+}$back transfer becomes peak-shaped as the scan increases. Indeed, the thickness of the diffusion layer in the organic phase becomes lower than the membrane thickness and hence $\mathrm{TBA}^{+}$ions are confined within the pores, leading to a linear diffusion.

\subsection{Conclusion}

Liquid-liquid micro-interfaces were modified by the electrochemically induced formation of mesoporous silica deposits. The modification process is based on the transfer of $\mathrm{CTA}^{+}$ions from the organic to an aqueous phase (controlled by the application of an interfacial potential difference), which catalyzes the condensation of hydrolyzed TEOS molecules in the aqueous phase. The silica deposition occurs on the aqueous side of the interface and cyclic voltammetric studies have shown that it is a process limited by the transfer of $\mathrm{CTA}^{+}$cations. Morphology (shape and dimension) of the deposit, determined by SEM and profilometry, is controlled by the amount of $\mathrm{CTA}^{+}$cations that is being transferred to the aqueous phase. Raman spectroscopy has confirmed that deposits are made of silica but it reveals the presence of both $\mathrm{CTA}^{+}$and ions from the electrolyte of the organic phase trapped in the silica matrix. After removal of these ions by calcination, the modified microinterfaces become porous to the transfer of model tetraalkylammonium ions $\left(\mathrm{TMA}^{+}\right.$and $\left.\mathrm{TBA}^{+}\right)$. 
The modification in-situ of an array of micro-interfaces with mesoporous silica opens a wide range of possibilities in the design of new sensors. Indeed, it would offers the advantages of both microscopic and nanoscopic scale. Such sensors would benefit from improved mass transport linked to the microscopic dimension of the interface. Furthermore, functionalization of the silica matrix with chemical groups of interest would provide selectivity at the nanoscale.

\subsection{Acknowledgements}

LP is grateful to Ecole Doctorale SESAMES (ED 412, Université de Lorraine) for his PhD grant and to Région Lorraine for financial support to the project. The authors are grateful to L. Salsi for SEM imaging, to Dr M. Dossot for his huge engagement and help with RAMAN experiments and data treatment, and to Dr Mathieu Etienne for his help with profilometry based on shear force measurements. Tyndall National Institute (Cork, Ireland) is acknowledged for supplying the silicon membranes.

\section{References}

(1) Stockmann, T. J.; Montgomery, A.-M.; Ding, Z. Determination of Alkali Metal Ion Transfers at Liquid|liquid Interfaces Stabilized by a Micropipette. J. Electroanal. Chem. 2012, 684, 612.

(2) Bingol, H.; Kaykal, F.; Akgemci, E. G.; Sirit, A. Facilitated Transfer of Alkali and AlkalineEarth Metal Ions by a Calix[4]arene Derivative Across Water/1,2-Dichloroethane Microinterface: Amperometric Detection of Ca2+. Electroanalysis 2010, 22, 2825-2833.

(3) Arrigan, D.W.M; Herzog, G; Scanlon, M.D; \& Strutwolf, J. Applications of Electrochemistry at Liquid-Liquid Microinterfaces. Electroanal. Chem. A Ser. Adv. 2013, 25, 105-178.

(4) Samec, Z. Electrochemistry at the Interface between Two Immiscible Electrolyte Solutions. Pure Appl. Chem. 2004, 76, 2147-2180.

(5) Edel, J. B.; Kornyshev, A. A.; Urbakh, M. Self-Assembly of Nanoparticle Arrays for Use as Mirrors, Sensors, and Antennas. ACS Nano 2013, 7, 9526-9532. 
(6) Arrigan, D. W. M. Bioanalytical Detection Based on Electrochemistry at Interfaces between Immiscible Liquids. Anal. Lett. 2008, 41, 3233-3252.

(7) Dryfe, R. A. W.; Holmes, S. M. Zeolitic Rectification of Electrochemical Ion Transfer. J. Electroanal. Chem. 2000, 483, 144-149.

(8) Lillie, G. C.; Dryfe, R. A. W.; Holmes, S. M. Zeolite-Membrane Modulation of Simple and Facilitated Ion Transfer. Analyst 2001, 126, 1857-1860.

(9) Senthilkumar, S.; Dryfe, R. A. W.; Saraswathi, R. Size-Selective Voltammetry: Modification of the Interface between Two Immiscible Electrolyte Solutions by Zeolite Y. Langmuir 2007, $23,3455-3461$.

(10) Walcarius, A. Analytical Applications of Silica-Modified Electrodes - A Comprehensive Review. Electroanalysis 1998, 10, 1217 - 1235.

(11) Wan, Y.; Zhao, D. On the Controllable Soft-Templating Approach to Mesoporous Silicates. Chem. Rev. 2007, 107, 2821-2860.

(12) Walcarius, A. Electroanalytical Applications of Microporous Zeolites and Mesoporous (Organo)Silicas: Recent Trends. Electroanalysis 2008, 20, 711-738.

(13) Walcarius, A. Template-Directed Porous Electrodes in Electroanalysis. Anal. Bioanal. Chem. 2010, 396, 261-272.

(14) Walcarius, A.; Sibottier, E.; Etienne, M.; Ghanbaja, J. Electrochemically Assisted SelfAssembly of Mesoporous Silica Thin Films. Nat. Mater. 2007, 6, 602-608.

(15) Goux, A.; Etienne, M.; Aubert, E.; Lecomte, C.; Ghanbaja, J.; Walcarius, A. Oriented Mesoporous Silica Films Obtained by Electro-Assisted Self-Assembly (EASA). Chem. Mater. 2009, 21, 731-741.

(16) Herzog, G.; Sibottier, E.; Etienne, M.; Walcarius, A. Electrochemically Assisted SelfAssembly of Ordered and Functionalized Mesoporous Silica Films: Impact of the Electrode Geometry and Size on Film Formation and Properties. Farad. Discuss. 2013, 164, 259-273.

(17) Etienne, M.; Goux, A.; Sibottier, E.; Walcarius, A. Oriented Mesoporous Organosilica Films on Electrode: A New Class of Nanomaterials for Sensing. J. Nanosci. Nanotechno. 2009, 9, 2398-2406.

(18) Herzog, G.; Vodolazkaya, N. A.; Walcarius, A. Platinum Ultramicroelectrodes Modified with Electrogenerated Surfactant-Templated Mesoporous Organosilica Films: Effect of Film Formation Conditions on Its Performance in Preconcentration Electroanalysis. Electroanalysis 2013, 25, 2595-2603.

(19) Rafiee, M.; Karimi, B.; Farrokhzadeh, S.; Vali, H. Hydroquinone Functionalized Oriented MCM-41 Mesochannels at the Electrode Surface. Electochim. Acta 2013, 94, 198-205.

(20) Rafiee, M.; Karimi, B.; Asl, Y. A.; Vali, H. Electrochemical Fabrication of Electroactive Ordered Mesoporous Electrode. Analyst 2013, 138, 1740-1744. 
(21) Mareček, V.; Jänchenová, H. Electrochemically Controlled Formation of a Silicate Membrane at a Liquid|liquid Interface. J. Electroanal. Chem. 2003, 558, 119-123.

(22) Niedziolka, J.; Opallo, M. Electrochemically Assisted Sol-gel Process at a Three Phase Junction. Electrochem. Commun. 2008, 10, 1445-1447.

(23) Poltorak, L.; Herzog, G.; Walcarius, A. In-Situ Formation of Mesoporous Silica Films Controlled by Ion Transfer Voltammetry at the Polarized Liquid-liquid Interface. Electrochem. Commun. 2013, 37, 76-79.

(24) Zazpe, R.; Hibert, C.; Lanyon, Y. H.; O’Brien, J.; Arrigan, D. W. M. Ion-Transfer Voltammetry at Silicon Membrane-Based Arrays of Micro-Liquid-Liquid Interfaces. Lab Chip 2007, 7, 1732-1737.

(25) Sepulveda, L.; Cortes, J. Ionization Degrees and Critical Micelle Concentrations of Hexadecyltrimethylammonium and Tetradecyltrimethylammonium Micelles with Different Counterions. J. Phys. Chem. 1985, 89, 5322-5324.

(26) Davies, T. J.; Compton, R. G. The Cyclic and Linear Sweep Voltammetry of Regular and Random Arrays of Microdisc Electrodes: Theory. J. Electroanal. Chem. 2005, 585, 63-82.

(27) Morf, W. E.; Rooij, N. F. De. Performance of Amperometric Sensors Based on Multiple Microelectrode Arrays. Sens. Actuators, B 2000, 44, 538-541.

(28) Atkins, P. W. Physical Chemistry; 4th ed.; Oxford University Press: Oxford, 1992.

(29) Bard, A. J.; Faulkner, L. R. Eletrochemical Methods: Fundamentals and Applications; 2nd Ed.; John Wiley and Sons: New York, 2001.

(30) Wilke, S.; Zerihun, T. Diffusion Effects at Microhole Supported Liquid/liquid Interfaces. Electrochim. Acta 1998, 44, 1-8.

(31) Dale, S. E. C.; Unwin, P. R. Polarised Liquid/liquid Micro-Interfaces Move during Charge Transfer. Electrochem. Commun. 2008, 10, 723-726.

(32) Silver, B. R.; Fülöp, V.; Unwin, P. R. Protein Crystallization at Oil/water Interfaces. New J. Chem. 2011, 35, 602.

(33) Gupta, R.; Chaudhury, N. K. Entrapment of Biomolecules in Sol-Gel Matrix for Applications in Biosensors: Problems and Future Prospects. Biosens. Bioelectron. 2007, 22, 2387-2399.

(34) Ho, M.; Pemberton, J. E. Alkyl Chain Conformation of Octadecylsilane Stationary Phases by Raman Spectroscopy . 1 . Temperature Dependence the Effect of Temperature on the Conformational Order of. Anal. Chem. 1998, 70, 4915-4920.

(35) Booth, S. G.; Cowcher, D. P.; Goodacre, R.; Dryfe, R. A. W. Electrochemical Modulation of SERS at the Liquid/liquid Interface. Chem. Commun. 2014, 4482-4484.

(36) González-Henríquez, C. M.; Terraza, C. a; Sarabia, M. Theoretical and Experimental Vibrational Spectroscopic Investigation of Two R(1)R(2)-Diphenylsilyl-Containing 
Monomers and Their Optically Active Derivative Polymer. J. Phys. Chem. B 2014, 118, $1175-1184$.

(37) Veres, M.; Füle, M.; Tóth, S.; Koós, M.; Pócsik, I. Surface Enhanced Raman Scattering (SERS) Investigation of Amorphous Carbon. Diam. Relat. Mater. 2004, 13, 1412-1415.

(38) Silvester, D. S.; Arrigan, D. W. M. Array of Water|room Temperature Ionic Liquid MicroInterfaces. Electrochem. Commun. 2011, 13, 477-479.

(39) Ishimatsu, R.; Kim, J.; Jing, P.; Striemer, C. C.; Fang, D. Z.; Fauchet, P. M.; McGrath, J. L.; Amemiya, S. Ion-Selective Permeability of an Ultrathin Nanoporous Silicon Membrane as Probed by Scanning Electrochemical Microscopy Using Micropipet-Supported ITIES Tips. Anal. Chem. 2010, 82, 7127-7134.

(40) Walcarius, A.; Delacote, C.; Sayen, S. Electrochemical Probing of Mass Transfer Rates in Mesoporous Silica-Based Organic-inorganic Hybrids. Electrochim. Acta 2004, 49, 37753783.

(41) Etienne, M.; Walcarius, A. Evaporation Induced Self-Assembly of Templated Silica and Organosilica Thin Films on Various Electrode Surfaces. Electrochem. Commun. 2005, 7, 1449-1456.

(42) Guillemin, Y.; Etienne, M.; Aubert, E.; Walcarius, A. Electrogeneration of Highly Methylated Mesoporous Silica Thin Films with Vertically-Aligned Mesochannels and Electrochemical Monitoring of Mass Transport Issues. J. Mater. Chem. 2010, 20, 6799_ 6807.

(43) Yantasee, W.; Lin, Y.; Fryxell, G. E.; Busche, B. J. Simultaneous Detection of Cadmium, Copper, and Lead Using a Carbon Paste Electrode Modified with Carbamoylphosphonic Acid Self-Assembled Monolayer on Mesoporous Silica (SAMMS). Anal. Chim. Acta 2004, 502, 207-212. 
Graphical abstract for Table of Contents

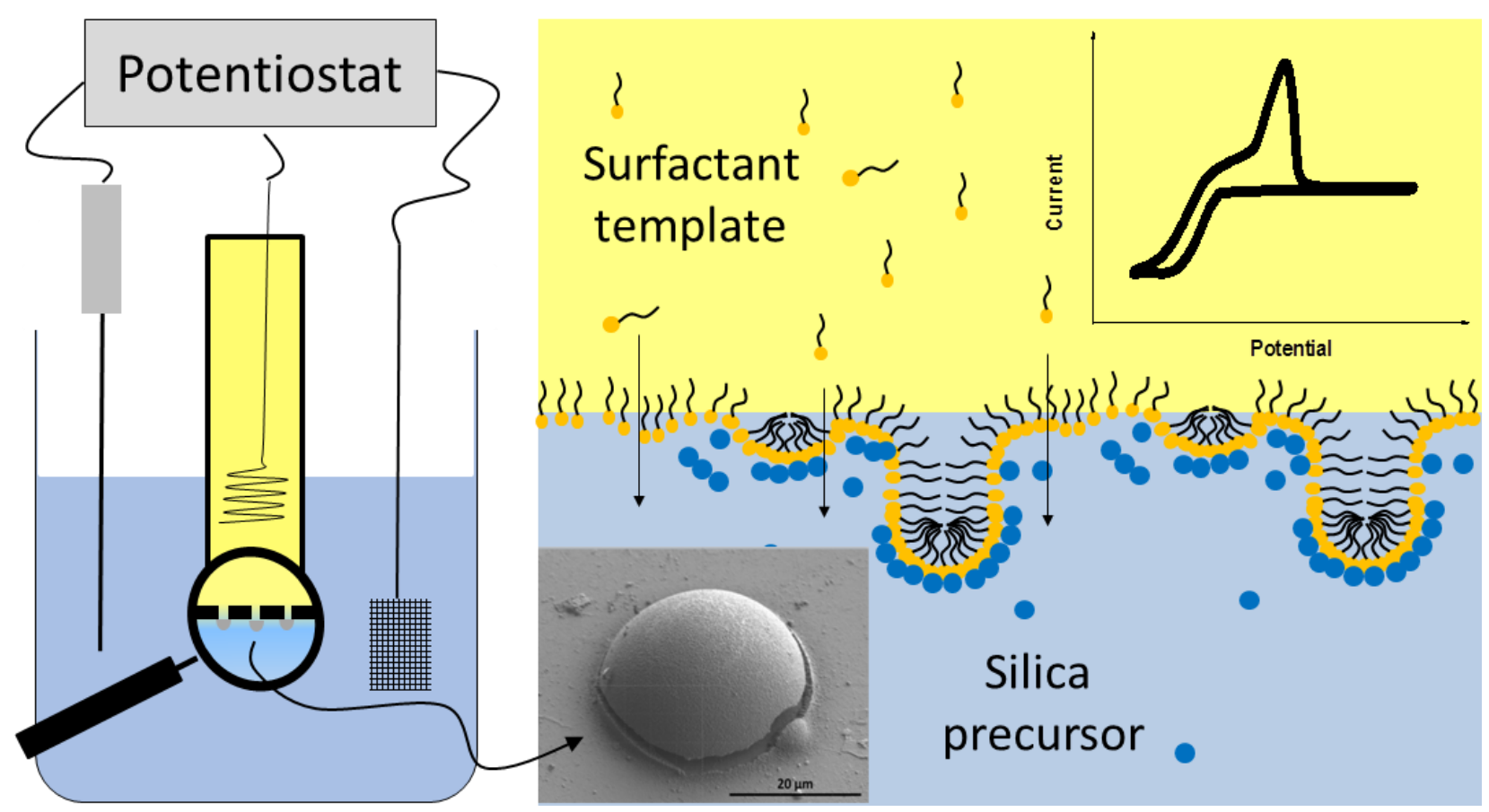

